\title{
A Large-Eddy Simulation Study of the Influence of Subsidence on the Stably Stratified Atmospheric Boundary Layer
}

\author{
Jeffrey D. Mirocha • Branko Kosović
}

Received: 31 December 2008 / Accepted: 3 September 2009 / Published online: 21 November 2009

(C) The Author(s) 2009. This article is published with open access at Springerlink.com

\begin{abstract}
The influence of the large-scale subsidence rate, $S$, on the stably stratified atmospheric boundary layer (ABL) over the Arctic Ocean snow/ice pack during clear-sky, winter conditions is investigated using a large-eddy simulation model. Simulations of two 24-h periods are conducted while varying $S$ between $0,0.001$ and $0.002 \mathrm{~m} \mathrm{~s}^{-1}$, and the resulting quasi-equilibrium ABL structures and evolutions are examined. Simulations conducted with $S=0$ yield a boundary layer that is deeper, more strongly mixed and cools more rapidly than the observations. Simulations conducted with $S>0$ yield improved agreement with the observations in the ABL height, potential temperature gradients and bulk heating rates. We also demonstrate that $S>0$ limits the continuous growth of the ABL observed during quasi-steady conditions, leading to the formation of a nearly steady ABL of approximately uniform depth and temperature. Subsidence reduces the magnitudes of the stresses, as well as the implied eddy-diffusivity coefficients for momentum and heat, while increasing the vertical heat fluxes considerably. Subsidence is also observed to increases the Richardson number to values in excess of unity well below the ABL top.
\end{abstract}

Keywords Arctic Ocean · Large-eddy simulation - Stable boundary layer · Subsidence

\section{Introduction}

The lower atmosphere over the Arctic Ocean is typically stable in the bulk sense, with temperature inversions commonplace, especially during periods of relative quiescence. However, in spite of the bulk stability, a shallow boundary layer featuring nontrivial turbulent mixing frequently occurs beneath the strong overlying inversion (Serezze et al. 1992). Strong stability extending to the surface of the snow/ice pack is often prevented by potentially many

J. D. Mirocha $(\varangle) \cdot$ B. Kosović

Lawrence Livermore National Laboratory, Livermore, CA 94550-9234, USA

e-mail: jmirocha@1lnl.gov

B. Kosović

e-mail: branko@ucar.edu 
processes, including turbulence induced by cloud-top cooling, vertical wind shear and breaking waves, as well as the conductive heat flux from the snow/ice pack interior, which constrains surface cooling.

Despite the existence of many turbulence-generating processes (e.g. Mahrt 1999), the mean atmospheric boundary-layer (ABL) depth over the Arctic Ocean is typically quite shallow, and mixing is often of only weak to moderate intensity, especially during clear-sky periods. Additionally, the Arctic ABL frequently exhibits significant variability in depth and intensity of mixing during periods featuring ostensibly similar forcing conditions. A possible explanation for many of these observed features of the behaviour of the Arctic ABL, particularly during clear-sky conditions, is the large-scale vertical velocity field.

In non-convective conditions and away from frontal boundaries, vertical motions in the atmosphere are typically several orders of magnitude smaller than the horizontal wind components, justifying their exclusion from large-scale, quasi-two-dimensional analysis. An additional factor motivating their exclusion whenever possible is the notorious difficulty of accurate measurement of the vertical velocity (Angevine 1997) However, large-scale subsiding motions in the atmosphere cannot always be neglected, since, although weak in relation to other motions, they are central to our understanding of many important large-scale features of the global circulation, including the semi-permanent high-pressure systems occurring over the planet's deserts and poles (Holton 2004).

In addition to planetary-scale circulations, subsidence influences many processes occurring at smaller scales as well. Among the small-scale processes showing sensitivity to subsidence, several involve the ABL. Under conditions of stable stratification, subsidence can affect the ABL dynamically, thermodynamically and chemically by modifying entrainment processes. The entrainment of heat is of particular importance to ABL dynamics and thermodynamics due to the increased buoyant destruction of turbulence kinetic energy (TKE), which can result in a shallower ABL and weaker mixing. Such issues are highly relevant to the climates of the high latitudes, and the Arctic in particular, where persistent stability and strong inversions of temperature and other quantities are frequently observed.

These and other features unique to the Arctic region, including unusual cloud types and surface conditions, low temperatures and low water vapour amounts (Curry et al. 1996) provide significant challenges to the modelling of the Arctic ABL. For these and other reasons, climate models have great difficulty modelling even the present Arctic climate (Walsh et al. 2002), while future climate change simulations routinely feature the largest spread in the Arctic region (Räisänen 2001). During the Arctic Regional Climate Model Intercomparison Project, in which six state-of-the-art regional climate models simulated the annual cycle over the Arctic Ocean, the ABL schemes performed poorly in many respects, particularly in their predictions of surface heat fluxes, which correlated with observations at $r<0.3$ (Tjernström et al. 2005).

Mirocha et al. (2005) discuss the importance of the large-scale subsidence rate in the vertical transfer of heat occurring within the lower atmosphere and between the atmosphere and the surface during four extended stable, predominantly clear-sky periods occurring over the Arctic Ocean snow/ice pack. They suggest that the strong cooling of the ABL due to turbulent heat exchange with the cold underlying surface is balanced primarily by the entrainment of heat from the overlying temperature inversion into the ABL, and its subsequent transfer downward through the ABL. The cooling of the entrainment zone above the ABL is, in turn, balanced by the interaction of weak subsiding motions with the strong temperature inversions occurring there. In this context, small variability in the subsidence rate, on the order of $0.001 \mathrm{~m} \mathrm{~s}^{-1}$, can affect the thermodynamic state of the ABL profoundly, potentially influencing turbulent exchanges with the surface as well. 
The present study utilizes a large-eddy simulation (LES) model to investigate the relationship between subsidence and ABL dynamics and thermodynamics proposed in Mirocha et al. (2005). Simulations of the stably stratified ABL over the Arctic Ocean snow/ice pack during two representative clear-sky, winter case studies are conducted with different subsidence rates, and the resulting differences in ABL structure and processes are described. The data used in the study are presented in Sect. 2, the methodology is introduced in Sect. 3, the case studies are described in Sect. 3.2, results are presented in Sect. 4, and a summary and conclusions are given in Sect. 5.

\section{Observations}

The data used in this study were obtained during the Surface Heat Budget of the Arctic Ocean (SHEBA) field experiment of 1997-1998. The SHEBA experiment collected observations from above the Arctic Ocean snow/ice surface for an entire year as the field camp, centered about the Canadian Coast guard icebreaker (the Des Groseilliers), drifted from $74^{\circ} \mathrm{N}$ to $81^{\circ} \mathrm{N}$ across the Beaufort and Chukchi Seas (Uttal 2002). The data of relevance to the present study were obtained from two in-situ measurement platforms within the SHEBA field camp, the GPS/Loran Atmospheric Sounding System (GLASS), and the Atmospheric Surface Flux Group (ASFG) 20-m instrumented tower and instrument site.

Time-height sections of temperature and contours of wind speed during the 96-h period comprising the basis of this study are shown in Fig. 1a. Temperature is shown to distinguish the sharp thermal inversions surmounting the shallow ABL, as well as to show the thermodynamic evolution of the atmospheric temperature field irrespective of pressure changes. Figure $1 \mathrm{~b}-\mathrm{d}$ contains the corresponding time series of surface sensible heat flux, $H_{\mathrm{s}}\left[\mathrm{W} \mathrm{m}^{-2}\right]$, with negative values denoting heat transfer into the surface, friction velocity, $u_{*}\left[\mathrm{~m} \mathrm{~s}^{-1}\right]$, and wind speed at $10 \mathrm{~m}, U_{10}\left[\mathrm{~m} \mathrm{~s}^{-1}\right]$, from the ASFG site.

The raw data used to create the time-height sections depicted in Fig. 1a were obtained from Vaisala RS 80-15GH radiosondes, launched from the ship deck approximately every $12 \mathrm{~h}$, at roughly 1100 and 2300 UTC. These data contained significant scatter within the lowest few tens of metres that required correction. The data containing the most scatter were replaced by interpolating (linearly for temperature, quadratically for wind speed) between the 10 - $\mathrm{m}$ values obtained from the ASFG tower and a height above most of the scatter (approximately $30 \mathrm{~m}$ for temperature, up to several hundred metres for the winds). All data above approximately $30 \mathrm{~m}$ were smoothed using seven-point running mean values, corresponding to physical distances of approximately $10-20 \mathrm{~m}$. The potential temperatures were computed using a hydrostatic pressure field computed from the surface pressure and the average of the 2.5- and 10-m temperatures. Given these caveats, Fig. 1 is intended to provide only a broad sketch of the lower atmospheric temperature and wind speed evolution throughout the period.

The hourly averaged friction velocities and sensible heat fluxes were computed from

$$
u_{*}=-\left[\left(\overline{w^{\prime} u^{\prime}}\right)^{2}+\left(\overline{w^{\prime} v^{\prime}}\right)^{2}\right]^{1 / 4}
$$

and

$$
H_{s}=\rho C_{p} \overline{w^{\prime} T^{\prime}}=\rho C_{p}\left(\overline{w^{\prime} T_{s n}^{\prime}}-0.51 \overline{w^{\prime} q^{\prime}}\right),
$$

where $\rho$ is the density, $C_{p}$ is the heat capacity of air, and $w^{\prime}, u^{\prime}, q^{\prime}$ and $T_{s n}^{\prime}$ are the perturbation vertical velocity, streamwise velocity, specific humidity and sonic virtual temperature, respectively. 

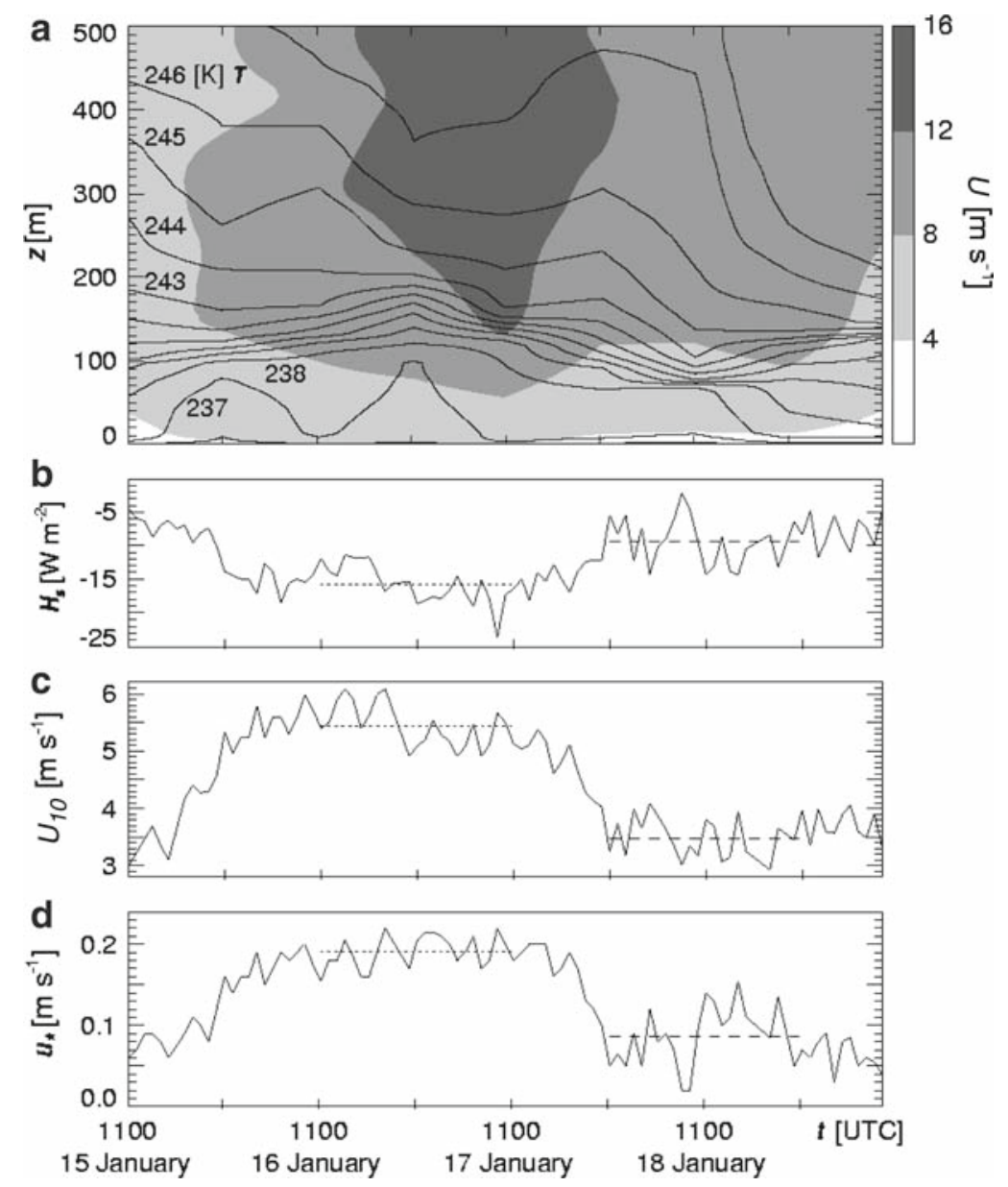

Fig. 1 Observations from 15 January, 1100 UTC to 19 January, 1100 UTC. a Time-height sections of temperature and wind speed (shaded); time series of (b) surface heat flux; c wind speed at $10 \mathrm{~m}$; $\mathbf{d}$ surface friction velocity. Dotted and dashed lines in b-d indicate 24-h averages during periods 1 and 2, respectively

The momentum and heat flux cospectra were obtained from $10-\mathrm{Hz}$ measurements at nominally five heights on the ASFG tower (only one height for specific humidity). Estimates of the hourly error and long-term bias of $u_{*}$ are \pm 0.05 and $\pm 0.015\left[\mathrm{~m} \mathrm{~s}^{-1}\right]$, while those of $H_{S}$ are \pm 4.1 and $\pm 0.8\left[\mathrm{~W} \mathrm{~m}^{-2}\right]$, respectively. The latent heat fluxes were nearly zero during the periods, yielding a negligible influence on the ABL, hence are ignored in the present study. Further details of the instrumentation and data processing used in the creation of the ASFG dataset may be found in Persson et al. (2002), or at the SHEBA ASFG website (http://www. weather.nps.navy.mil/ p psguest/sheba/).

During the period shown in Fig. 1, the atmospheric temperatures both within and above the ABL are nearly steady, before increasing slightly over the last $24 \mathrm{~h}$ (Fig. 1a). The wind speeds are low at the beginning of the period, increase to moderate values between approximately hours 12-60, then weaken again for the remainder (Fig. 1a, c). Both $u_{*}$ and $H_{S}$ qualitatively follow the changes in wind speed, with small values initially changing to larger 
values between approximately hours 12-60, followed by smaller values again (Fig. 1b, d). The values of $H_{S}$ are persistently negative, thus acting as a continual sink of heat (and TKE) within the ABL throughout the period. The dotted and dashed horizontal lines appearing in Fig. 1b-d indicates 24-h averages of each variable during periods 1 and 2, respectively; their utility to the study is described in the following section.

\section{Methodology}

The LES technique is utilized to investigate the properties and behaviour of the ABL during the period described above. The LES approach was chosen as it represents the stateof-the-art computational paradigm for the numerical investigation of high-Reynolds-number atmospheric flows. The difficulties that often undermine the effectiveness of other turbulence modelling strategies, including higher-order Reynolds-average Navier-Stokes closures, are addressed in the LES approach via the explicit calculation of all scales of the flow of importance to turbulence generation. Only the smallest scales of the flow, those responsible chiefly for dissipation, are parameterised.

\subsection{The Large-Eddy Simulation Model}

We use the LES model of Kosović and Curry (2000), based on Moeng (1984), to solve the filtered, incompressible conservation equations for momentum and potential temperature:

$$
\frac{\partial u_{i}^{r}}{\partial t}=\varepsilon_{i j k} u_{j}^{r} \omega_{k}^{r}-\frac{1}{\rho} \frac{\partial \Pi^{r}}{\partial x_{i}}-\frac{1}{\rho} \frac{\partial \sigma_{i j}}{\partial x j}-\frac{g}{\theta_{0}} \theta^{r} \delta_{i j}-f_{c} \varepsilon_{i j 3} u_{j}^{r}
$$

and

$$
\frac{\partial \theta^{r}}{\partial t}=-u_{j}^{r} \frac{\partial \theta^{r}}{\partial x_{j}}-\frac{\partial \vartheta_{j}}{\partial x_{j}} .
$$

Here, $u_{i}^{r}$ is the resolved velocity field, $\omega_{k}^{r}$ is the resolved vorticity field, $\Pi^{r}$ is the modified resolved pressure field, $\theta^{r}$ is the resolved potential temperature field, $\theta_{0}$ is the reference temperature used in the Boussinesq buoyancy approximation, $f_{c}$ is the Coriolis parameter and $\sigma_{i j}$ and $\vartheta_{j}$ are the subfilter-scale (SFS) stresses and heat fluxes, respectively. The SFS component of the flow is parameterized using the nonlinear SFS stress model of Kosović (1997), which was developed to account for the effects of backscatter and anisotropy, each of which is important in the stable, shear-driven ABL, such as is the focus of this study. The SFS heat flux is a gradient-diffusion scheme following Deardorff (1980).

Equations 3 and 4 are discretized spectrally in the horizontal directions and use secondorder finite differences in the vertical. The filtering procedure uses a wave cut-off in the horizontal directions, with no explicit filtering used in the vertical. These equations, as well as those for the SFS stresses, fluxes and TKE, are solved using a third-order Runge-Kutta time-integration scheme.

To permit examination of the role of subsidence in ABL dynamics and thermodynamics, specified profiles of mean subsidence rate, $S$, were superimposed onto the resolved vertical velocity field during the simulations. The imposed profiles of $S$, shown in Fig. 2, are smooth cubic functions of height within the lowest $50 \mathrm{~m}$, and constant above. The tangents of the cubic functions vanish at $50 \mathrm{~m}$ and at the surface, at which heights the functions take the specified constant value and zero, respectively. The height of $50 \mathrm{~m}$ was chosen to fall below 
Fig. 2 Imposed profiles of vertical velocity

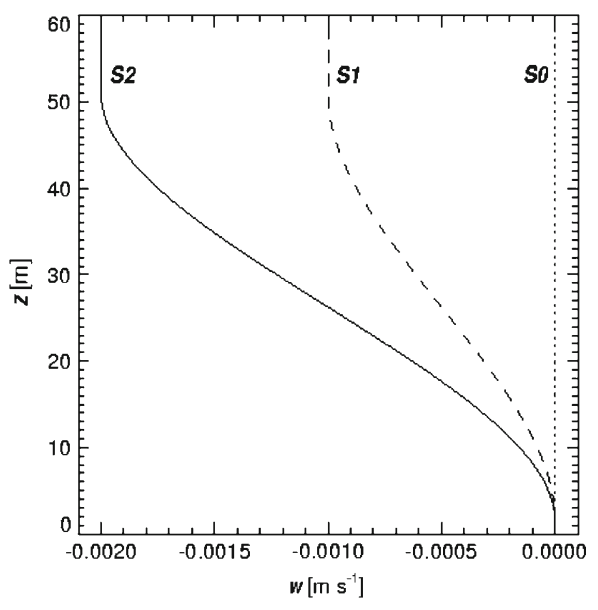

the top of the shallowest observed ABL, preventing the imposed vertical velocity profile shape itself from influencing the equilibrium ABL height.

The computational algorithm of the LES model assumes incompressibility, which was maintained in spite of the imposed mean vertical velocity gradient by introducing a counterbalancing resolved-scale mass sink

$$
\frac{\partial u_{j}^{r}}{\partial x_{j}}=-\frac{\partial \bar{w}}{\partial x_{3}} .
$$

This relationship arises from the vanishing of the horizontal gradients of the domainaveraged horizontal velocity components and divergence.

Longwave radiative heating rates were computed from the vertical profile of horizontally averaged temperature within the LES domain using the Rapid Radiative Transfer Model (RRTM) (Mlawer et al. 1997). The column temperature and water vapour mixing ratio values above the LES domain used by RRTM are provided from the soundings, with standard atmospheric values used in the far upper portion. A constant relative humidity (over liquid saturation) of $80 \%$ within the lowest $1 \mathrm{~km}$, decreasing to the mean value over all of the soundings taken during the two periods above, was maintained throughout the simulations. Mirocha et al. (2005) estimated that the contribution of radiation relative to turbulence was small within the ABL, however it was similar to the other terms in the thermodynamic budget (advective and adiabatic heating arising from subsidence) aloft. Hence the radiative effects are calculated chiefly to provide a first-order forcing to counteract the subsidence-induced heating above the ABL. The radiative heating rates were updated every $10 \mathrm{~min}$ during the simulations.

The computational domain for each simulation was $512 \mathrm{~m}$ in each horizontal direction and $384 \mathrm{~m}$ in the vertical direction. The domain was discretized using 128 nodes in each horizontal direction and 384 nodes in the vertical direction, yielding gridcells $4 \times 4 \times 1 \mathrm{~m}^{3}$. The explicit filter uses a sharp cut-off with a length of approximately $12 \mathrm{~m}$ in the horizontal directions.

The choice of the computational domain reflects an emphasis on resolving the smallscale features important to stable ABL flows, while also permitting the long integration times required for the $\mathrm{ABL}$ to approach equilibrium with the three imposed mean subsidence rates. These priorities, in light of computational constraints, precluded use of a domain of 
sufficient size to resolve larger-scale structures, such as gravity waves, whose effects are possibly significant as well.

\subsection{Case Studies}

The basis of this study consists of large-eddy simulations of the ABL depicted in Fig. 1. However, due to the above discussed errors in variables used to force and evaluate simulations, the focus is shifted from duplication of the observations towards simulation of the idealized ABL structure and evolution, characterized by subsets of the data presented in Figs. 1 and 2, for which representative values of the measured variables may instead be utilized.

The data presented in Figs. 1 and 2 can be interpreted as representative of two distinct $\mathrm{ABL}$ regimes. The first regime, which will be referred to as period 1, is characterized by observations from 16 January 1100 to 17 January 1100 UTC, 1998. The second regime, which will be referred to as period 2 , is characterized by observations made from 17 January 2300 to 18 January 2300 UTC, 1998.

Period 1 features a deeper ABL, with higher wind speeds at $10 \mathrm{~m}$, larger friction velocities and larger sensible heat fluxes than for period 2. The average values of these parameters during periods 1 and 2, shown in Table 1, are indicated in Fig. 1 by the horizontal dotted and dashed lines, respectively. Also shown in Table 1 are characteristic values of the large-scale geostophic winds, $U_{g}$, (estimated from the sounding data) used to force the simulations.

The upper boundary conditions imposed during the simulations were free slip for the horizontal velocity components $u$ and $v$, while the mean vertical velocity, $\bar{w}$, hereafter denoted the mean subsidence rate, $S$, was specified as depicted in Fig. 2. The resolved vertical velocity, $w^{r}$, obeys the radiative condition following Klemp and Durran (1983). The lower boundary conditions include the surface friction velocity, given by Monin-Obukhov similarity theory, following Moeng (1984), using a roughness length of $0.01 \mathrm{~m}$, and the sensible heat flux, whose values are given in Table 1.

The influence of $S$ on the quasi-equilibrium ABL dynamics and thermodynamics is the key focus of this investigation. Values of $S=0,0.001$ and $0.002 \mathrm{~m} \mathrm{~s}^{-1}$, heretofore denoted $S 0, S 1$ and $S 2$, (Fig. 2) respectively, were used to force the simulations. These values are based on estimates given in Mirocha et al. (2005) which were obtained by comparing the vertical temperature advection term to the vertical flux divergence term in a bulk energy balance equation for the ABL. In the absence of significant thermal forcing from other sources (horizontal advection, radiation or latent effects), the nearly constant temperatures observed within the ABL over time imply a first-order balance between vertical temperature advection and flux divergence. This balance provides a means for the estimation of $S$. The values of $S$ chosen for the simulations comprising the present study represent a range about the value of $S \approx 0.0015 \mathrm{~m} \mathrm{~s}^{-1}$, estimated during the 72-h period investigated by Mirocha et al. (2005).

Each of the simulations was initialized with a potential temperature profile based on the 18 January, 1100 UTC sounding, which featured the shallowest observed ABL, with data

Table 1 Observed values of geostrophic wind, $U_{g}$, wind speed at $10 \mathrm{~m}, u_{10}$, surface friction velocity, $u_{*}$, and surface sensible heat flux, $H_{S}$, during periods 1 and 2

\begin{tabular}{llllc}
\hline & $U_{g}\left[\mathrm{~m} \mathrm{~s}^{-1}\right]$ & $u_{10}\left[\mathrm{~m} \mathrm{~s}^{-1}\right]$ & $u_{*}\left[\mathrm{~m} \mathrm{~s}^{-1}\right]$ & $H_{S}\left[\mathrm{~W} \mathrm{~m}^{-2}\right]$ \\
\hline Period 1 & 12 & 5.43 & 0.19 & -15.82 \\
Period 2 & 7 & 3.48 & 0.09 & -9.38
\end{tabular}


below $50 \mathrm{~m}$ replaced with a neutral profile of $\theta=232 \mathrm{~K}$. The simulations of each period were initialized with $u=U_{g}$ and $v=0$, and forced at the surface with the average values of $H_{S}$ given in Table 1 . Random perturbations of approximately $0.1 \mathrm{~K}$ and $0.1 \mathrm{~m} \mathrm{~s}^{-1}$ were added to stimulate turbulence, and the initial SFS TKE was specified as $0.2(1-z / 50)^{3} \mathrm{~m}^{2} \mathrm{~s}^{-2}$ below $50 \mathrm{~m}$. Two "spin-up" simulations were performed using no imposed subsidence rate, for $12 \mathrm{~h}$, for each value of $U_{g}$. The $S 1$ and $S 2$ simulations were integrated further using the hour 12 data from the $S 0$ simulations as initial conditions, and continued until the ABL height had achieved nearly steady values for $4 \mathrm{~h}$. The $S 0$ simulations were continued for an additional $6 \mathrm{~h}$ beyond hour 12 to demonstrate the quasi-steady ABL growth. The results of all simulations are presented in the following section.

\section{Results}

Mean profiles of potential temperature, wind speed, vertical heat and momentum fluxes, eddy diffusivity coefficients, gradient and flux Richardson numbers and velocity spectra are presented in this section.

\subsection{Potential Temperature and Wind Speed Profiles}

Figure 3 depicts equilibrium LES potential temperature and wind speed profiles during periods 1 (left) and 2 (right). The profiles depict plane-averaged values from the end of the fourth hour of integration after equilibration of the ABL to a nearly-constant height. Simulations using $S 0, S 1$ and $S 2$ are indicated by dotted, dashed and solid lines, respectively. Data from the three soundings from each period are shown in grey with asterisks, triangles and squares depicting data from 16 January, 1100, 16 January, 2300 and 17 January, 1100 UTC, respectively, during period 1, and 17 January, 2300, 18 January, 1100 and 18 January, 2300 UTC, respectively, during period 2 .
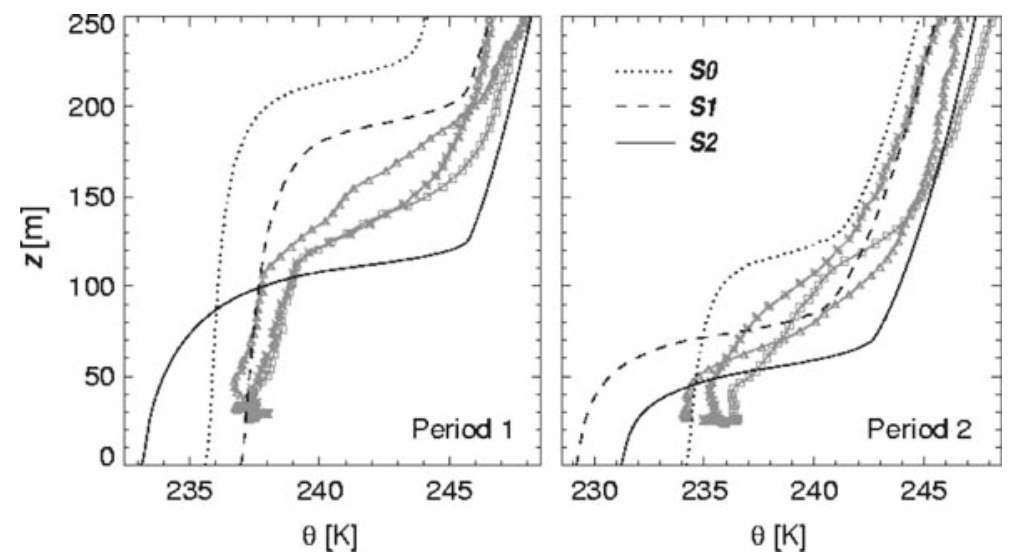

Fig. 3 Simulated (black) and observed (grey) profiles of potential temperature during period 1 (left) and 2 (right). Data from the three soundings from each period are shown in grey with asterisks, triangles and squares depicting observations from 16 January, 1100 UTC, 16 January, 2300 and 17 January, 1100 UTC, respectively, during period 1, and 17 January, 2300 UTC, 18 January, 1100 UTC and 18 January, 2300 UTC, respectively, during period 2 
Figure 3 clearly demonstrates the profound influence of $S$ on both the ABL depth and, to a lesser but still nontrivial extent, the vertical gradients of potential temperature. The equilibration times for the $S 1$ and $S 2$ cases during period 1 were 2 and $48 \mathrm{~h}$, respectively. The relatively short equilibration time of the $S 1$ case is the serendipitous result of the ABL height during the spin-up having grown in $12 \mathrm{~h}$ to almost exactly the $S 1$ equilibrium height. The $S 2$ case equilibrated much more slowly due to the long time period required for the weak subsiding motion to reduce the ABL height by nearly $100 \mathrm{~m}$ from its 12 -h value. During period 2, the equilibrium heights of each ABL forced with non-zero subsidence were obtained after $36 \mathrm{~h}$. As the $S 0$ profiles are shown after only an additional $6 \mathrm{~h}$ of integration beyond hour 12 , these technically are not equilibrium heights, as these boundary layers are still growing, and were the simulations extended to match the time scales of equilibrations of the other simulations, the differences in depth likely would have been much greater.

The sounding data indicate that the ABL heights and potential temperature gradients within the ABL from the $S 1$ and $S 2$ simulations yield greater agreement with the observations. However, the absolute values of the potential temperature from each of the simulations must be interpreted carefully. Due to the manner in which the simulations were conducted, transient influences on the entrainment at the ABL top influenced the absolute potential temperatures within the ABL in an artificial manner. During the initial 12-h spin-up, the absence of subsidence permitted rapid boundary-layer growth. The subsequent rapid entrainment of heat into the $\mathrm{ABL}$ during the growth of the $\mathrm{ABL}$ nearly counterbalanced the cooling at the surface due to the negative sensible heat fluxes, causing a very gradual cooling of the ABL overall. For the $S 1$ and $S 2$ simulations, subsidence was applied beginning at the 13th hour, the immediate effect of which was to accelerate entrainment into the ABL top. This increased buoyant destruction in the upper ABL resulted in a temporary decoupling of the upper from the lower ABL, with only the lower ABL remaining strongly coupled to the surface. This resulted in the lower portion of the ABL cooling very rapidly due to its contact with the surface, while the inversion base slowly descended. After many hours, subsidence forced the inversion base downward sufficiently so that turbulence generated at the surface impinging upon the now shallower ABL top was strong enough to persist in spite of the strong buoyant destruction. This led to an increase in the entrainment rate, altering the bulk ABL thermodynamic trend. The result is that during $S 1$ and $S 2$ the ABL cooled for several hours before the entrainment-induced warming began. This resulted in artificial discrepancies between the bulk ABL temperatures among the simulations that are not relevant.

To clarify interpretation of the thermodynamic behaviour of the ABL during these simulations, Fig. 4 shows the equilibrium ABL heating rates (left) by plotting the final planeaveraged potential temperatures (dotted) relative to their values $4 \mathrm{~h}$ earlier (dashed). The profiles have been shifted arbitrarily to enable more straightforward comparisons among the simulations; only the differences between the profiles at time $t$ and $t+4$ hours from simulation forced with the same value of $S$ are meaningful.

Quasi-equilibrium wind speed profiles (right) are also shown in Fig. 4, plotted at $2 \mathrm{~m} \mathrm{~s}^{-1}$ increments. Subsidence is observed to have two effects on the wind speed profiles. Firstly, subsidence reduces the magnitude of the wind-speed maximum relative to the geostrophic values above. However, despite the reduced maximum, the corresponding decrease of ABL height leads to an increased wind-speed gradient across the ABL.

The effects of subsidence on the quasi-equilibrium bulk ABL heating rates are considerable. Although the $S 0$ ABL cools slowly after $18 \mathrm{~h}$, these are not equilibrium cooling rates, as the $\mathrm{ABL}$ is still growing and entraining heat from above. The addition of subsidence alters the bulk ABL heating rates considerably. The $S 1$ simulations yield weak cooling (a few K per day) during each period, which, while greater than the cooling from the $S 0$ simulations, 

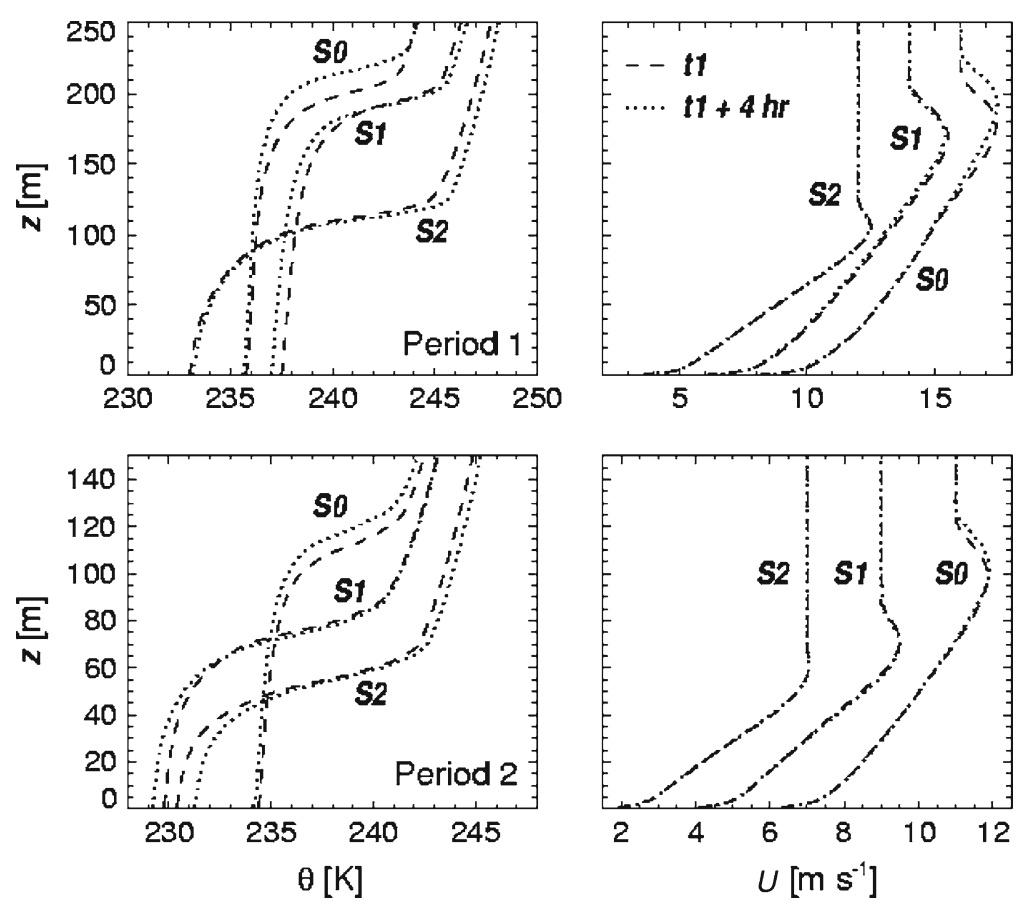

Fig. 4 Potential temperature (left) and wind speed (right) evolution from time $t$ (dashed) to $t+4$ hours (dotted) for simulations of period 1 (top) and 2 (bottom)

is achieved with no further $\mathrm{ABL}$ growth. The $S 2$ simulations yield changes to the sign of the temperature tendency within the ABL, resulting in weak heating during period 1 and stronger heating during period 2 . These results show that weak subsiding motions can result in nearly steady boundary-layer behaviour during periods of constant forcing (geostrophic wind and surface heat flux).

The $S 1$ and $S 2$ simulations mimic the nearly steady behaviour of both the boundarylayer depth and heating rates that were observed during the case study periods depicted in Fig. 1. These simulations provide an independent confirmation of the estimates by Mirocha et al. (2005) that a mean subsidence rate of approximately $0.0015 \mathrm{~m} \mathrm{~s}^{-1}$ would balance the thermodynamic budgets and provide nearly steady ABL behaviour during these periods.

Figure 5 shows the actual values of the simulated wind speed from each of the simulations in the lowest $10 \mathrm{~m}$ relative to observations obtained from the ASFG tower. The triangles and squares show the observed wind speeds at 2.5 and $10 \mathrm{~m}$, averaged over periods 1 and 2 . Increasing subsidence is seen to have reduced the mean wind speeds in each case. During period 1, $S 1$ has little effect, as the influence of weak subsidence relative to the stronger shear-driven mixing is small near the surface. During the $S 2$ simulation, the subsidence forcing is of sufficient strength to significantly affect the ABL dynamics even near the surface. During period 2, the weaker shear-driven mixing, due to the lower geostrophic wind, allows the weaker subsiding motions during $S 1$ to exact a much more significant influence on the ABL near the surface.

The wind speeds near the surface and the friction velocity, $u_{*}$, are related. The simulated mean equilibrium values of $u_{*}$, computed over the last hour of each simulation, were much larger than their observed values, shown in Table 2 . The simulated values of $u_{*}$ shown in 
Fig. 5 Simulated (lines) and observed wind speeds at 2.5 and $10 \mathrm{~m}$ (symbols) during periods 1 (right) and 2 (left)

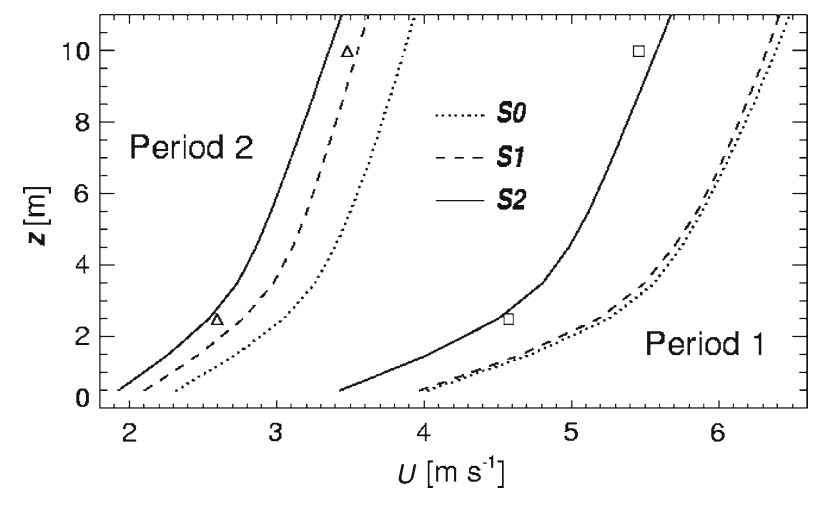

\begin{tabular}{llcc}
\cline { 2 - 3 } $\begin{array}{l}\text { Table } 2 \text { Observed and simulated } \\
\text { surface friction velocities, } u_{*},\end{array}$ & $u_{*}\left[\mathrm{~m} \mathrm{~s}^{-1}\right]$ & Period 1 & Period 2 \\
\cline { 2 - 4 } during periods 1 and 2 & Observed & 0.19 & 0.09 \\
& $S 0$ & 0.365 & 0.201 \\
& $S 1$ & 0.342 & 0.177 \\
& $S 2$ & 0.295 & 0.163 \\
\hline
\end{tabular}

Table 2 Observed and simulated surface friction velocities, $u_{*}$, during periods 1 and 2

Table 2 are the maxima occurring within the vertical profile, which occurred a few grid points above the surface due to the slightly non-monotonic nature of the simulated vertical stress profiles (see Fig. 6). The larger-than-observed simulated values of $u_{*}$ were due, in part, to the use of an artificially enhanced value of the roughness length, $z_{0}=0.01 \mathrm{~m}$. The enhancement of $z_{0}$ was required to constrain the magnitudes of the simulated near-surface wind speeds, which were too large when using representative values for $z_{0}$ (bulk surface fluxes from the ASFG tower were computed using $z_{0}=0.00045 \mathrm{~m}$, e.g.). Such behaviour points to a failure of the surface similarity formulation, as applied in most LES (see Moeng 1984). An important parameter in turbulence production in the stable ABL is vertical wind shear, with the wind speed at the lowest grid point playing a key role. As $u_{*}$ is used only to determine the surface stress, which, in turn, influences the velocity at the first grid point above the surface, for the purposes of this study the actual value of $u_{*}$ is not as important as the resulting velocity. Hence, rather than using smaller values of $z_{0}$, leading to a better prediction of $u_{*}$, but large errors in the low-level velocities, we chose instead to use an enhanced $z_{0}$, producing larger errors in $u_{*}$, but yielding better low-level velocities.

The important result is that the $S 1$ and $S 2$ simulations indicate that even small subsidence rates that attenuate to trivial values at $10 \mathrm{~m}$ can strongly influence the velocity field at and below $10 \mathrm{~m}$, and act to retard the near-surface winds.

\subsection{ABL Height}

The ABL height is likewise found to depend strongly on the subsidence rate. The $S 0$ simulations of this study exhibited continued growth throughout the 18-h duration of the simulations. The S1 and S2 simulations, by contrast, ceased to grow after 12 hours, instead equilibrating to nearly constant heights, with the larger subsidence rates corresponding to shallower ABL heights for each of the forcing scenarios. 

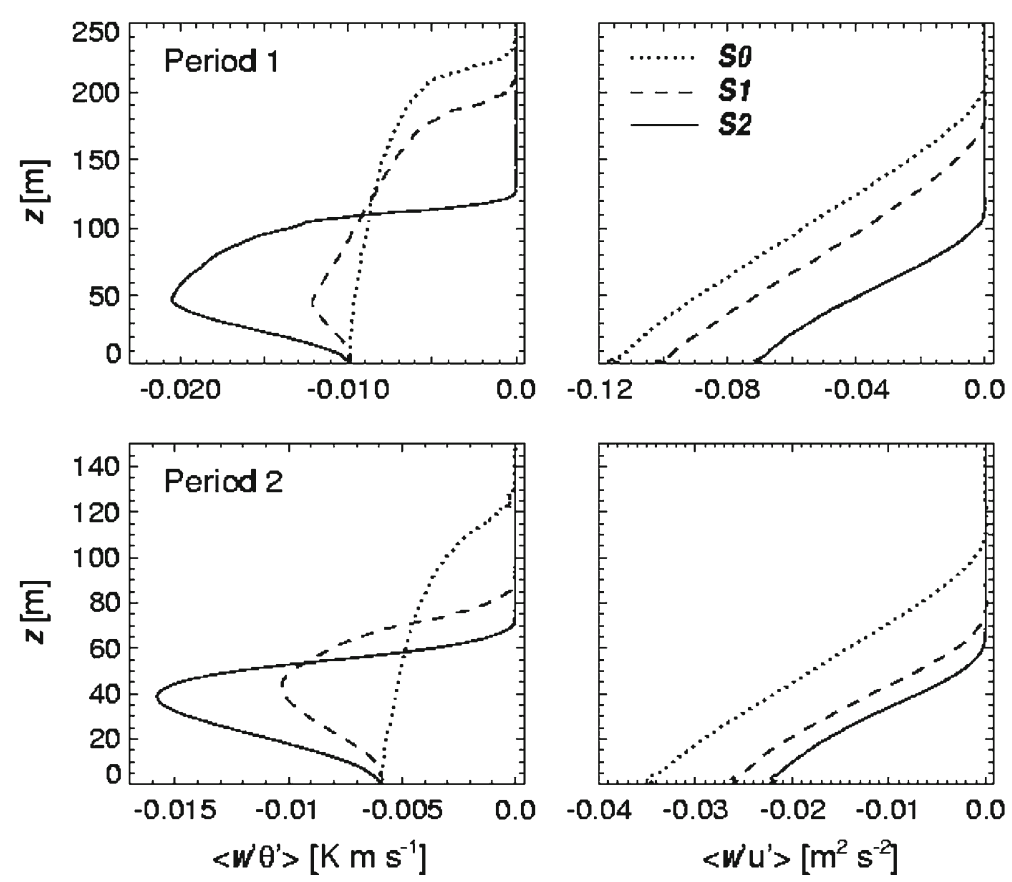

Fig. 6 Simulated profiles of vertical heat flux (left) and vertical streamwise stress (right)

While there exist many methods for estimating the ABL height, depending upon the availability of measured or computed parameters, for the simulations conducted in this study, the resolved-scale stress components were explicitly computed, hence we follow the often-used methodology of using the height at which the tangential stress falls below a percentage of the surface value (Caughey et al. 1979; Derbyshire 1990). We used a value of five percent of the maximum value occurring within the vertical profile, (due to the slightly non-monotonic nature of the simulated stress profiles near the surface) and extrapolated to the height at which $u_{*}$ would vanish if the profile were linear,

$$
h=z\left(\left[u_{*}^{2}(z)<0.05 \max \left(u_{*}^{2}(z)\right)\right]\right) / 0.95 .
$$

Such an approach for the determination of $h$ is clearly only applicable to the boundary layer for which turbulence is primarily surface-driven, and maintained continuously throughout the depth of the boundary layer. With increasing stability, or when the key turbulence-generating process occur above the surface (such as in the cloud-topped boundary layer) the turbulence can become discontinuous in time and/or in space, and lose its connection with the surface, in which case the above-mentioned method for its determination becomes tenuous. For the simulations conducted in this study, the geostrophic forcing was sufficiently strong relative to other processes to maintain continuous, surface-based mechanical mixing, hence continuous stresses, throughout the depth of the ABL. Table 3 presents the ABL heights from each of the simulations obtained from Eq. 6. While the values for the $S 1$ and $S 2$ simulations are the nearly steady equilibrium heights, those from the $S 0$ simulations were computed after hour 18 , at which point the ABL was still growing. 
Table 3 Simulated

boundary-layer heights, $h$, during periods 1 and 2

\begin{tabular}{llc}
\hline$h[\mathrm{~m}]$ & Period 1 & Period 2 \\
\hline$S 0$ & 203 & 110 \\
$S 1$ & 178 & 74 \\
$S 2$ & 110 & 62 \\
\hline
\end{tabular}

\subsection{Vertical Mixing}

Figure 6 shows the total (resolved + subfilter) vertical fluxes of heat (left) and streamwise vertical stress (right) during periods 1 (top) and 2 (bottom). These data were time- and plane-averaged from simulation results at 2 -min increments, for $20 \mathrm{~min}$.

As seen in Fig. 6, increasing subsidence has an opposite effect on the heat and momentum fluxes, increasing the former while decreasing the latter. The $S 2$ simulation during period 2 featured a greater heat flux throughout most of the ABL than the $S 0$ and $S 1$ simulations during period 1, even though the momentum fluxes were nearly an order of magnitude smaller.

The opposing trends in the behaviours of the heat and momentum fluxes with increasing subsidence rate are due both to increased entrainment of heat into the ABL top and to increased potential temperature gradients within the ABL. Each of these factors increases the rate of TKE destruction due to buoyancy effects. However, despite the increases in buoyant suppression of turbulence, there remains sufficient mechanical forcing provided by the applied geostrophic forcing to maintain active turbulence throughout the shallow, subsidenceforced ABL during these simulations. Hence, while the turbulence is weakened, resulting in reduced momentum fluxes, the mechanically forced turbulence that remains is able to entrain and transport heat very efficiently throughout the $\mathrm{ABL}$ in the presence of a stronger temperature gradient.

That each sensible heat flux profile converges to the same surface value during each period results from imposing the sensible heat flux as a surface boundary condition. In reality, the surface heat fluxes likely vary with the subsidence rate. A goal of this study was to investigate the role of subsidence in balancing the bulk ABL cooling implied by the observed surface heat fluxes, motivating imposing the heat flux rather than surface temperature (which, due to potential errors in parameterization or forcing data, could have yielded fluxes with different averages from the observations). While surface fluxes should not be used as a boundary condition in strongly stable regimes, the ABL simulated herein is only weakly stable (Basu et al. 2008).

Figure 7 shows time- and plane-averaged implied LES eddy diffusivity coefficients for momentum (left) and heat (right) during periods 1 (top) and 2 (bottom) obtained from

$$
K_{m}=\overline{w^{\prime} u^{\prime}}\left(\frac{\partial \bar{u}}{\partial z}\right)^{-1},
$$

and

$$
K_{h}=\overline{w^{\prime} \theta^{\prime}}\left(\frac{\partial \bar{\theta}}{\partial z}\right)^{-1}
$$

The gradient appearing in the denominator of the expression for $K_{m}$ nearly vanishes near the ABL top during these idealized simulations (see Fig. 4), hence data above the local minima occurring just below $h$ are omitted. As with the momentum fluxes shown in Fig. 6, both $K_{h}$ and $K_{m}$ decrease significantly within the ABL with increasing values of $S$. 

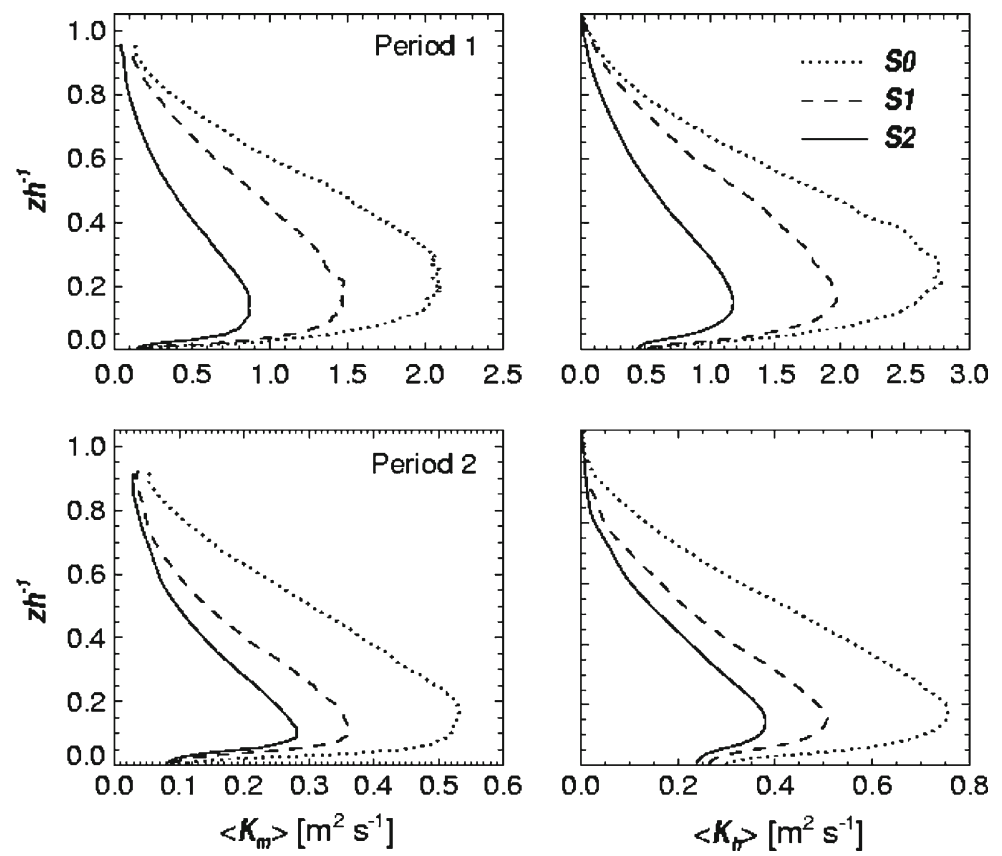

Fig. 7 Profiles of effective eddy diffusivity coefficients for momentum (left) and heat (right)
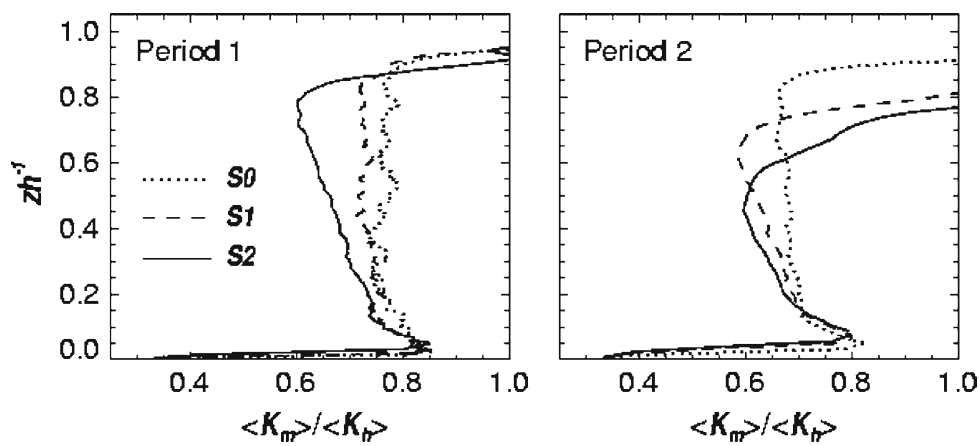

Fig. 8 Profiles of turbulent Prandtl number during periods 1 (left) and 2 (right)

Figure 8 shows time- and plane-averaged ratios of the turbulent Prandtl number, $\mathrm{Pr}=$ $K_{m} / K_{h}$, during periods 1 (left) and 2 (right). The decrease of $P r$ with increasing subsidence within the middle and upper ABL indicates that subsidence affects the turbulent diffusion of momentum and heat differently, decreasing $K_{m}$ more so than $K_{h}$ with height throughout the $\mathrm{ABL}$, due to the increased downward heat flux into the ABL relative to that of momentum. The increase of $P r$ in the upper ABL is a consequence of the heat flux vanishing at a lower height within the ABL than the shear stress does (see Fig. 6). Subsidence is seen to exacerbate this difference.

Figure 9 shows the time- and plane-averaged gradient (top) and flux (bottom) Richardson numbers, $R i_{g}$ and $R i_{f}$, respectively, during periods 1 (left) and 2 (right), computed from 

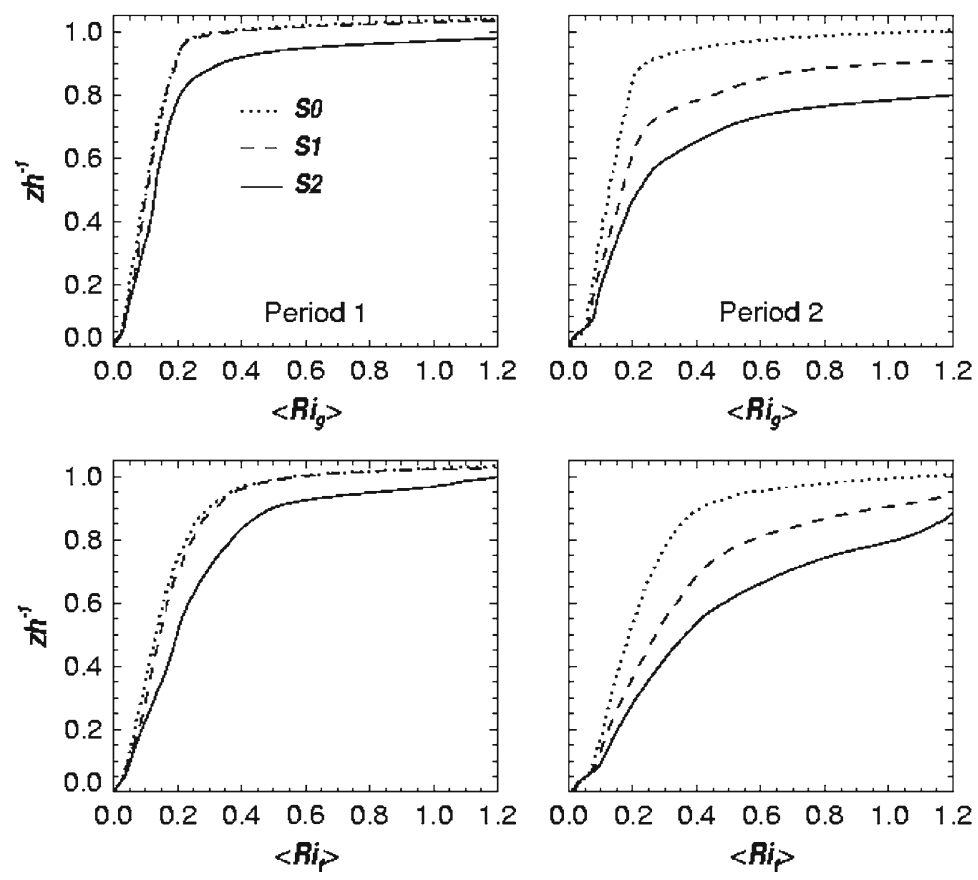

Fig. 9 Profiles of gradient (top) and flux (bottom) Richardson numbers

$$
R i_{g}=\frac{g}{\bar{\theta}} \frac{\partial \bar{\theta}}{\partial z}\left[\left(\frac{\partial \bar{u}}{\partial z}\right)^{2}+\left(\frac{\partial \bar{v}}{\partial z}\right)^{2}\right]^{-1}
$$

and

$$
R i_{f}=\frac{g \overline{w^{\prime} \theta^{\prime}}}{\bar{\theta}}\left(\overline{w^{\prime} u^{\prime}} \frac{\partial \overline{u_{i}}}{\partial z}+\overline{w^{\prime} v^{\prime}} \frac{\partial \overline{u_{i}}}{\partial z}\right)^{-1} .
$$

Critical values of these Richardson numbers are often used as a threshold for the onset $(R i<0.2-0.25)$ or decay $(R i>1)$ of turbulence (e.g. Stull 1988). However a growing body of evidence indicates that turbulence can persist for values of $R i \gg 1$ (e.g. Galperin et al. 2007). Our simulations support these observations, particularly during the subsiding cases forced by the weaker geostrophic wind. During the $S 1$ and $S 2$ simulations of period 2, $R i_{g}$ and $R i_{f}$ values in excess of unity were observed to occur significantly below the ABL top.

\subsection{Spectra}

Figure 10 depicts time-and plane-averaged streamwise velocity spectra averaged at 2-min increments for $20 \mathrm{~min}$ during periods 1 (left) and 2 (right). The spectra shown at four heights, $0.05,0.1,0.5$ and $0.9 h$, are indicated by the solid, dotted, dashed and dotted-dashed lines, respectively. Figure 10 reveals that in nearly every case the effects of subsidence cause a shift in spectral power to higher frequencies. This effect is hypothesized to be due to both a lower boundary-layer height as well as increased buoyant destruction in the upper boundary layer 

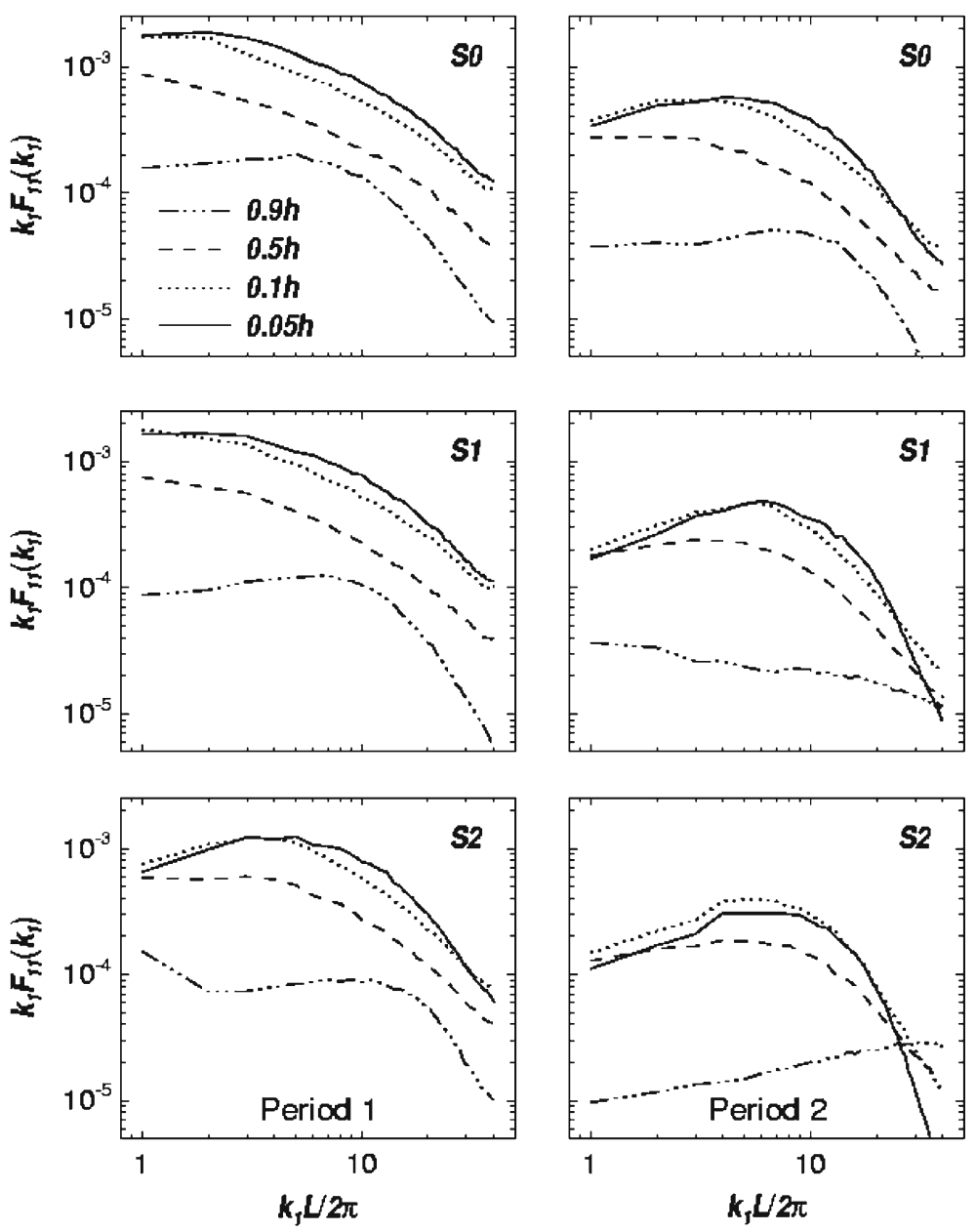

Fig. 10 Streamwise $u$-velocity spectra at four heights above the surface

reducing the intensity of the largest eddies. The most significant increase in the frequency of peak spectral power occurs during the $S 2$ simulation of period 2, in which case the subsidence forcing is strongest relative to shear production. In this case the inertial subrange near the ABL top has been shifted to scales smaller than are resolved by the LES. As such, while the results appear reasonable, caution should be exercised in interpretation.

Streamwise potential temperature spectra corresponding to those shown in Fig. 10 are shown in Fig. 11. The potential temperature spectra differ qualitatively from the velocity spectra in several ways. First, while the velocity components contain relatively low power in the upper ABL, the potential temperature spectra contain the highest power in the upper ABL. $S 1$ and $S 2$ also increase the spread among the spectral power distribution at different heights within the ABL. This effect is most noticeable during period 2, during which the influence of subsidence is stronger relative to shear. As with the velocity spectra, the $S 1$ and $S 2$ simulations during period 2 reveal that the inertial subrange is again shifted beyond the resolution of the LES. 

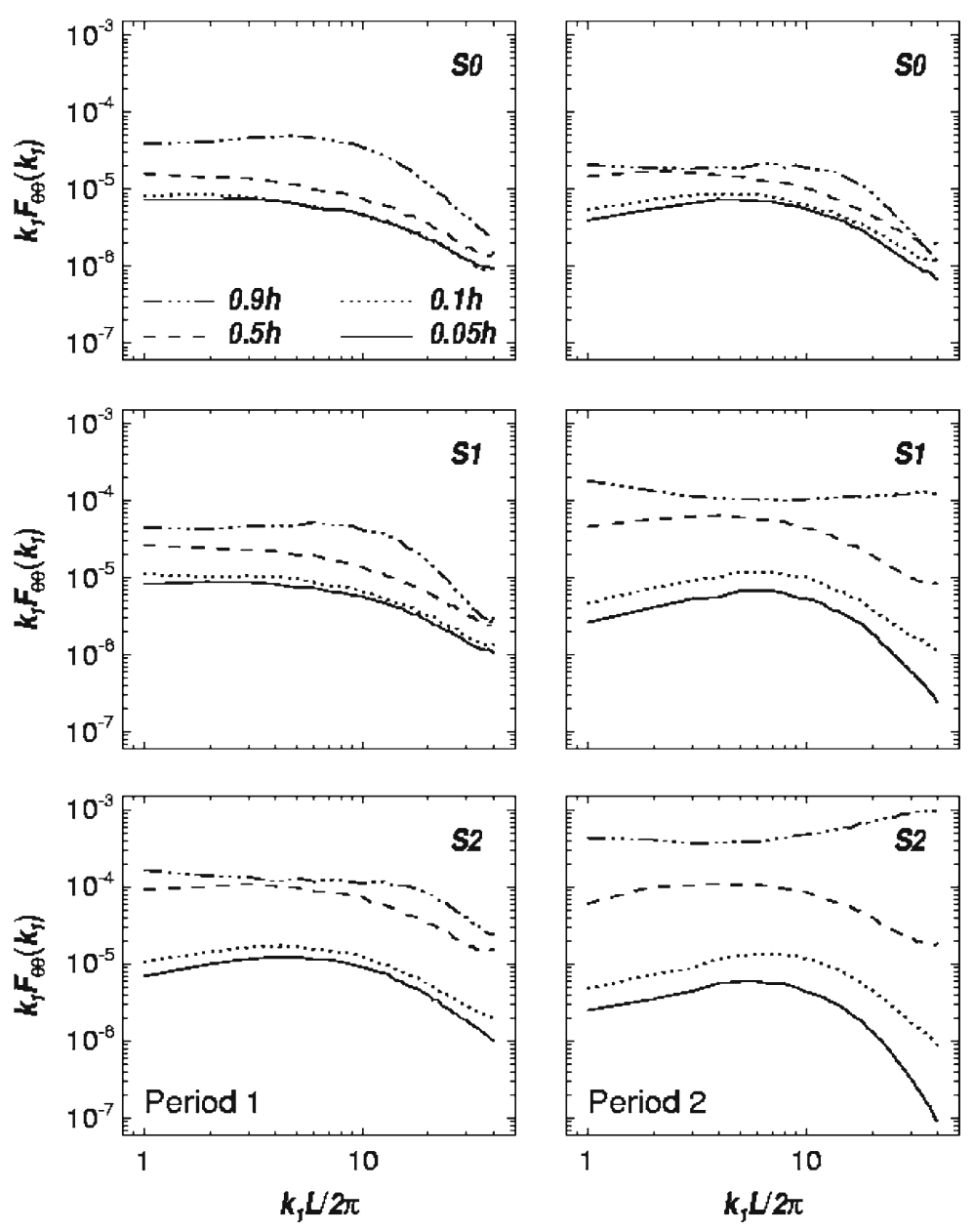

Fig. 11 Streamwise potential temperature spectra at four heights above the surface

\section{Summary and Conclusions}

The stably stratified ABL occurring over the Arctic Ocean was investigated using large-eddy simulations of two characteristic stable, clear-sky periods occurring during the winter. The influence of weak subsiding motions on several ABL parameters was examined by varying the large-scale subsidence rate, $S$, between $0,0.001$ and $0.002 \mathrm{~m} \mathrm{~s}^{-1}$. The simulations with $S=0$ generated ABL structures that diverged in many important respects from the observations, including deeper and stronger mixing, and more rapid-than-observed cooling. The introduction of subsidence not only decreased ABL heights significantly, but also resulted in weaker mixing within the ABL and decreased the bulk cooling rate of the ABL. Each of the simulations forced with subsidence showed significantly improved agreement with the observations relative to the non-subsidence simulations.

The addition of subsidence reduced the intensity of the vertical-streamwise momentum flux, as well as the eddy diffusivity coefficients for momentum and heat, while increasing 
the vertical heat fluxes. Subsidence likewise increased the strength of potential temperature gradients down which turbulence transported heat throughout the ABL toward the surface. In addition, subsidence increased the gradient and flux Richardson numbers, especially during period 2, during which values in excess of unity were observed at significant depths below the ABL top.

The results of the study clearly demonstrate the profound effects of small subsidence rates on the stably stratified ABL, in the presence of strong overlying thermal inversions, and in the absence of strong forcing from other processes. The ubiquity of thermal inversions in the Arctic is well established (e.g. Kahl 1990), highlighting the relevance of the large-scale vertical motion field to $\mathrm{ABL}$ dynamic and thermodynamic properties, entrainment rates, and the vertical mixing of heat, momentum and other constituents into and throughout the ABL.

The magnitude of the influence of such small values of $S$ on ABL behaviour is somewhat surprising, given the small values of $S$ we used relative to other estimates of $S$ and their effects appearing throughout the literature (e.g. Carlson and Stull 1986). However, the persistent stability encountered in the Arctic relative to the shorter-lived nocturnal stable ABL occurring at lower latitudes over land allows relatively weaker forcing to exact a considerable cumulative effect. If the relative importance of such small subsidence rates to ABL evolution and behaviour is found to be a general feature of the long-lived, stable ABL, then the implications for their impact throughout the polar regions during the low-sun seasons strongly motivate further investigation.

These results suggest that $S$ is likely to be an important external scaling parameter for the nearly steady, clear-sky boundary layer. The simulations presented herein, while suggestive, are not sufficiently numerous to support attempts at generalization. However, they do indicate a potentially fruitful avenue for such work in the future.

The influence of large-scale subsidence on the long-lived, stable ABL potentially affects many other important processes as well. Of particular relevance is the influence of the downward transfer of heat into and through the ABL and into the surface of the underlying snow/ice pack. During clear-sky conditions, strong radiative cooling of the surface relative to other terms in the surface heat budget can induce a rapid loss of heat from the snow/ice pack interior. As discussed in Mirocha et al. (2005), the nearly steady surface temperatures occurring during the clear-sky, winter periods of this study require that the differences between the average radiative cooling of the surface and sensible heat fluxes must have been balanced by the conductive heat flux from within the snow/ice pack interior. In this manner, sensible heat exchange plays a potentially significant role in the growth/ablation of the snow/ice pack.

An additional important physical process influenced by ABL dynamics is the low-level cloud field. The unabated growth and cooling of the ABL during the non-subsiding simulations conducted in this study would likely have eventually resulted in cloud formation, which would have profoundly altered the radiative budget of the lower atmosphere and surface.

While the relationships between subsidence, ABL height, entrainment, eddy diffusivity, vertical heat and momentum fluxes, temperature and velocity and cloud processes are complex, and require further study, a few general conclusions can be drawn from our study. The simulations suggest that, for a given ABL wind shear, in the limit of weak subsidence, small changes in $S$ exert a considerable influence on ABL height, but affect the bulk ABL temperature minimally. Conversely, when subsidence rates are larger, further increases in $S$ exert a diminishing influence on the ABL depth, but significantly affect the entrainment and bulk ABL heating rates. A given velocity shear appears to imply a given minimum depth 
required for the stresses to be dissipated, and this minimum depth is approached as subsidence strengthens.

The limit of relatively stronger subsidence, or correspondingly, the limit of minimum ABL height, has important consequences for the exchanges of heat with the underlying surface. The simulations comprising this study suggest that the observed ABL heights, particularly during period 2, were approaching their minimum limits. During period 2, increasing $S$ from 0.001 to $0.002 \mathrm{~m} \mathrm{~s}^{-1}$ had a relatively smaller effect on the ABL height than the increase from 0 to $0.001 \mathrm{~m} \mathrm{~s}^{-1}$. However, the thermodynamic effects of the former increase were considerably larger, resulting in much stronger downward fluxes of heat and bulk ABL heating. During period 1 the mean observed ABL height still showed a considerable decrease under the same increase of $S$. However, the ABL did begin to warm as a result, indicating that the effects of subsidence may have been undergoing transition from primarily modulating ABL height to more strongly modulating ABL heating.

These results imply two potential consequences in models that accurately depict the interactions between subsidence and the overlying temperature inversions. In the limit of relatively weak subsidence rates, errors in $S$ will likely yield significant errors in ABL height, while the impact on the ABL heat budget may be minimal. However, in the limit of stronger subsidence, while ABL height may be well predicted, errors in $S$ are likely to yield significant errors in thermodynamic evolution and surface heat exchange. This implies that improvement in the parameterization of ABL height alone, while a useful first step, does not guarantee improved representation of thermodynamic processes within the $\mathrm{ABL}$, or between the ABL and its boundaries, in the presence of subsidence.

These results point to complex relationships among the different parameters governing stable ABL evolution and structure in the Arctic. The determination of useful scaling relationships, while beyond the scope of this study, will greatly assist consolidation of understanding and improving parameterization strategies.

Although our simulations were conducted for clear-sky conditions, the strong vertical gradients of temperature, humidity and cloud and ice forming nuclei characteristic of the Arctic atmosphere suggest that large-scale subsiding motions are important during cloudy periods as well, particularly periods of persistent stratocumulus that are frequently observed. Significant changes in stratocumulus have been associated with small changes in the mean subsidence rate on the order of a few $\mathrm{mm} \mathrm{s}^{-1}$, leading to suggestions that there is an optimal range of subsidence rates for stratocumulus, with weaker subsidence being associated with other cloud morphologies (Norris and Klein 2000), while stronger subsidence may lead to dissolution of the stratocumulus deck (Weaver and Ramanathan 1997). In the Arctic, the role of subsidence in cloud processes is likely magnified by the characteristic increase of aerosol concentration above the ABL.

The persistence of anticyclonic conditions in the Arctic region highlights the significance of further investigation of the role of subsidence in this climatologically sensitive and crucially important region of the Earth. The challenges are daunting, however, for a number of reasons. Foremost among these is the lack of suitable observations. The computational complexity and expense of generating suitable data numerically remain, but are improving. However, further observations of the stably stratified ABL, particularly in the presence of subsidence, will be required both to improve fundamental understanding and to validate models. At the other end of the modelling spectrum, issues related to the large-scale numerical weather prediction paradigm, both in terms of the resolution of key features and processes related to ABL parameterization, as well as the relationships between the ABL and other physical parameterizations within the model, stand out as key challenges. Despite these difficulties, the profound effects of subsidence on the ABL and potentially cloud and surface 
physics provide ample motivation for future research and subsequent improvements for the next generation of high-latitude climate models.

Acknowledgements Many thanks to Judith Curry, who provided crucial support for this work, and to Julie Lundquist and Hugh Morrison, each of whom contributed many valuable discussions. We also thank our colleagues in the SHEBA Atmospheric Surface Flux Group, Ed Andreas, Chris Fairall, Peter Guest, and Ola Persson for help in collecting and processing the data. The National Science Foundation supported this research with grants to the U.S. Army Cold Regions Research and Engineering Laboratory, NOAA's Environmental Technology Laboratory, and the Naval Postgraduate School. Finally, we thank the anonymous reviewers for their helpful comments. Part of this work was performed under the auspices of the U.S. Department of Energy by Lawrence Livermore National Laboratory, in part under Contract W-7405-Eng-48 and in part under Contract DE-AC52-07NA27344. The research was also funded by a grant from the National Science Foundation Arctic Systems Science Program.

Open Access This article is distributed under the terms of the Creative Commons Attribution Noncommercial License which permits any noncommercial use, distribution, and reproduction in any medium, provided the original author(s) and source are credited.

\section{References}

Angevine WM (1997) Errors in mean vertical velocity measured by boundary layer wind profilers. J Atmos Ocean Technol 14:565-569

Basu S, Holtslag AAM, Van De Wiel BJH, Moene AF, Steeneveld G-J (2008) An inconvenient "truth" about using sensible heat flux as a surface boundary condition in models under stably stratified regimes. Acta Geophys Pol 56:88-99

Carlson MA, Stull RB (1986) Subsidence in the nocturnal boundary layer. J Clim Appl Meteorol 25: 1088-1099

Caughey SJ, Wyngaard JC, Kaimal JC (1979) Turbulence in the evolving stable boundary layer. J Atmos Sci 36:1041-1052

Curry JA, Rossow WB, Schramm JL (1996) Overview of arctic cloud and radiation properties. J Clim 9: $1731-1764$

Deardorff JW (1980) Stratocumulus-capped mixed layers derived from a three-dimensional model. Boundary-Layer Meteorol 18:495-527

Derbyshire SH (1990) Nieuwstadt's stable boundary layer revisited. Q J Roy Meteorol Soc 116:127-158

Galperin B, Sukoriansky S, Anderson PS (2007) On the critical Richardson number in stably stratified turbulence. Atmos Sci Lett 8:65-69

Holton JR (2004) An introduction to dynamic meteorology, 4th edn. Elsevier Academic Press, Amsterdam, $535 \mathrm{pp}$

Kahl JD (1990) Characteristics of the low-level temperature inversion along the Alaskan arctic coast. Int J Climatol 10:537-548

Klemp JB, Durran DR (1983) An upper boundary condition permitting internal gravity wave radiation in numerical mesoscale models. Mon Weather Rev 111:430-444

Kosović B (1997) Subgrid-scale modelling for the large-eddy simulation of high-Reynolds-number boundary layers. J Fluid Mech 336:151-182

Kosović B, Curry JA (2000) A Large eddy simulation of a quasi-steady, stably stratified atmospheric boundary layer. J Atmos Sci 57:1052-1068

Mahrt L (1999) Stratified atmospheric boundary layers. Boundary-Layer Meteorol 90:375-396

Mlawer EJ, Taubman SJ, Brown PD, Iacono MJ, Clough SA (1997) Radiative transfer for inhomogeneous atmospheres: RRTM a validated correlated-k model for the longwave. J Geophys Res 102:16663-16682

Mirocha JD, Kosović B, Curry JA (2005) Vertical heat transfer in the lower atmosphere over the Arctic Ocean during clear-sky periods. Boundary-Layer Meteorol 117:37-71

Moeng C-H (1984) A large-eddy simulation model for the study of planetary boundary-layer turbulence. J Atmos Sci 41:2052-2062

Norris JR, Klein SA (2000) Low cloud type over the ocean from surface observations. Part III: Relationship to vertical motion and the regional surface synoptic environment. J Clim 13:245-256

Persson POG, Fairall CW, Andreas EL, Guest PS, Perovich DK (2002) Measurements near the Atmospheric Surface Flux Group tower at SHEBA: Site description, data processing, and accuracy estimates. NOAA 
Tech. Memo. OAR ETL (available at the National Technical Information Service, 5285 Port Royal Road, Springfield, VA 22061)

Räisänen J (2001) $\mathrm{CO}_{2}$-induced climate change in CMIP2 experiments: quantification of agreement and role of internal variability. J Clim 14:2088-2104

Serezze MC, Kahl JD, Schnell RC (1992) Low-level temperature inversions of the Eurasian Arctic and comparison with Soviet island data. J Clim 5:599-613

Stull R (1988) An introduction to boundary layer meteorology. Kluwer, Dordrecht, 670 pp

Tjernström M, Žagar M, Svensson G, Cassano J, Pfeifer S, Rinke A, Wyser K, Delthoff K, Jones C, Semmler T (2005) Modelling the Arctic boundary layer: an evaluation of six ARCMIP regional-scale models with data from the SHEBA experiment. Boundary-Layer Meteorol 117:337-381

Uttal T et al (2002) The surface heat budget of the Arctic Ocean. Bull Am Meteorol Soc 83:255-275

Walsh JE, Kattsov WM, Chapman WL, Govorkova V, Pavlova T (2002) Comparison of Arctic climate by uncoupled and coupled global models. J Clim 15:1429-1446

Weaver CP, Ramanathan V (1997) Relationships between large-scale vertical velocity, static stability, and cloud radiative forcing over northern hemisphere extratropical oceans. J Clim 10:2817-2887 